\title{
FAKTOR-FAKTOR KEBERHASILAN WIRAUSAHA MAHASISWA BERBASIS MARKETING MIX 7P
}

\section{Susantiningrum, Edy Legowo, L.V. Ratna Devi Sakuntalawati, Dyah Yuni Kurniawati, Irsyadul Ibad, Nur Rahmi Akbarini}

\author{
Pusat Pengembangan Kewirausahaan LPPM Universitas Sebelas Maret, Jl. Ir. Sutami No. 36 A, \\ Kentingan, Jebres Surakarta, Indonesia, 57126 \\ Email: susantiningrum@staff.uns.ac.id
}

\begin{abstract}
ABSTRAK
Tingkat keberhasilan Program Mahasiswa Wirausaha (PMW) di beberapa perguruan tinggi dalam menghasilkan Wirausaha Baru (WUB) masih belum optimal. Faktor kegagalan lebih mendominasi siswa PMW daripada faktor keberhasilan. Oleh karena itu, tujuan penelitian ini adalah menganalisis faktorfaktor keberhasilan berwirausaha mahasiswa berdasarkan Bauran Pemasaran 7P. Metode penelitian yang digunakan adalah penelitian kuantitatif deskriptif, dimana hasil penelitian yang diperoleh dari perhitungan indikator-indikator diperkuat dengan dukungan studi kepustakaan sehingga lebih memperkuat analisa peneliti dalam membuat suatu kesimpulan. Hasil penelitian menunjukkan bahwa pada usaha kuliner dan non kuliner, faktor keberhasilan yang sama yaitu pada elemen price, promotion, place, people dan process. Pada usaha kuliner, non kuliner dan jasa, faktor keberhasilan yang sama terletak pada elemen process saja. Kesamaan yang tidak terdapat di semua elemen, menunjukkan bahwa faktor keberhasilan yang terdapat di tiga kelompok usaha, memiliki keunikan masing-masing.
\end{abstract}

Kata kunci: Bauran Pemasaran 7P, Faktor Keberhasilan, Kewirausahaan Mahasiswa

ABSTRACT
The level of success of PMW in several universities in producing new entrepreneurs (WUB) is still not optimal. Failure factors dominate PMW students more than success factors. Therefore, the purpose of this study is to analyze the success factors of student entrepreneurship based on the 7P Marketing Mix. The research method used is quantitative research. The results showed that in culinary and nonculinary businesses, the same success factors are in the elements of price, promotion, place, people and process. In culinary, non-culinary and service businesses, the same success factor lies in the process element. The similarities that do not exist in all elements, indicate that the success factors found in the three business groups have their own uniqueness

Keywords: Marketing Mix 7P, Student Entrepreneurship, Success Factors 


\section{PENDAHULUAN}

Pada tahun 2016 wirausaha Indonesia mencapai angka 3,10\% dari total penduduk yang berjumlah 225 juta jiwa. Kondisi ini sudah melampaui batas minimal yang di kemukakan McClelland, bahwa untuk menjadi negara yang makmur, perlu didukung oleh minimum jumlah wirausahawannya $2 \%$ dari populasi penduduk (Romli, 2019). Hal ini menjadi concern perguruan tinggi untuk memunculkan Wirausaha Baru (WUB) melalui beberapa program. Beberapa hasil penelitian menunjukkan bahwa tingkat keberhasilan Program Wirausaha Mahasiswa (PMW) di beberapa Perguruan Tinggi dalam menghasilkan WUB masih belum optimal. Tingkat keberhasilan PMW di Universitas Brawijaya tahun 2012, hanya $10 \%$ mahasiswa yang benarbenar menjalankan usahanya dan berhasil (Ratnasari et al., 2013). Di Universitas Pendidikan Ganesha (Undiksha) tingkat keberhasilan PMW pada tahun 2012 secara keseluruhan memiliki persentase sebesar 35\% (Sativana et al., 2014).

Memaknai realita pelaksanaan PMW ternyata belum berhasil sepenuhnya membentuk paradigma mahasiswa untuk meyakini prospek wirausaha, sehingga belum dapat berkomitmen sebagai wirausaha (Hartono, 2018). Faktor yang paling dominan mempengaruhi kegagalan usaha penerima PMW di Undiksha tahun 2013 adalah faktor kompeten dalam manajerial, faktor pengalaman dan faktor keuangan (Wartika, 2015). Faktor kegagalan juga terjadi pada penerima PMW tahun 2018 di
Universitas Negeri Padang (UNP), antara lain tidak kompeten dalam hal pengelolaan usaha, kurangnya kemampuan mevisualisasikan usaha, mengkoordinasikan, mengelola sumber daya maupun mengintegrasikan operasional perusahaan, kurangnya manajemen keuangan, lokasi yang kurang memadai, kurangnya pengawasan serta sikap kurang bersungguhsungguh dalam berusaha (Endriani \& Hasrul, 2020).

Faktor-faktor yang mempengaruhi keberhasilan program mahasiswa tahun 2018 di UNP antara lain kemauan dan kemampuan, tekad yang kuat dan kerja keras, kesempatan dan peluang, dan pengalaman dalam pekerjaan. Faktorfaktor ini diacu dari pendapat Suryana tentang faktor keberhasilan kewirausahaan (Endriani \& Hasrul, 2020). Hal ini sejalan dengan pendapat (Suarmawan, 2015) yang mengemukakan bahwa kesuksesan suatu bisnis usaha tergantung pada ide, peluang dan pelaku bisnis. Nilai tersebut harus tercermin dalam ide atau visi bisnis yang jelas (Suryana, 2016). Visi bisnis terwujud dalam bentuk strategi bisnis. Strategi bisnis mempunyai pengaruh positif terhadap kinerja usaha (Wheelen \& Hunger, 2012).

Studi oleh Rosnani dan Soaib Asimiran menunjukkan bahwa wirausaha membutuhkan strategi bisnis yang inovatif untuk menyediakan barang dan jasa yang lebih kompetitif dan layak untuk menghadapi perubahan dalam lingkungan bisnis saat ini (Widayati et al., 2019). Strategi pemasaran yang tepat diperlukan untuk 
mempertahankan keberlanjutan usaha (Harini \& Yulianeu, 2018). Kinerja pemasaran merupakan ukuran prestasi dari aktifitas proses pemasaran secara menyeluruh. Dewi dalam (Hartanty \& Rahmawati, 2013) menyatakan bahwa keunggulan bersaing yang dimiliki oleh perusahaan akan berdampak positif terhadap kinerja pemasarannya. Kinerja pemasaran dapat diukur dengan lima indikator, antara lain dengan kinerja secara keseluruhan (overall performance), pertumbuhan pangsa pasar (market share), pertumbuhan penjualan (sales growth), keuntungan (profitability) dan kepuasan pelanggan (customer satisfaction) (Rohmaniyah \& Nurhayati, 2017). Penerapan bauran pemasaran sebagai sebuah alat pemasaran akan berdampak terhadap kinerja pemasaran yang akan mempengaruhi keberhasilan usaha (Ruliah \& Susanto, 2015).

Bauran pemasaran atau marketing mix menurut Kotler dan Amstrong merupakan kumpulan alat pemasaran yang terorganisir dan terintegrasi dengan baik untuk mencapai tujuan pemasaran dengan efisien (Setiawan \& Harmon, 2017). Marketing mix 7P, menurut Alma adalah implementasi bauran pemasaran 4P (product, price, promotion, dan place) yang ditambahkan 3P yaitu people (personil), process (proses) dan physical evidence (sarana fisik) yang merupakan bauran pemasaran pada bisnis jasa (Marcelina \& Tantra, 2017). Adapun konsep dari masing-masing elemen adalah Product: Pengertian product (produk) menurut (Kotler, P., dan Armstrong, 2013) adalah segala sesuatu yang dapat ditawarkan ke pasar untuk mendapatkan perhatian, dibeli, digunakan, atau dikonsumsi yang dapat memuaskan keinginan atau kebutuhan pemakainya (Marcelina \& Tantra, 2017). Produk dipandang penting oleh konsumen dan dijadikan dasar pengambilan keputusan pembelian (Loekito et al., 2019). Price: Harga adalah kesepakatan nilai yang menjadi persyaratan bagi pertukaran dalam sebuah transaksi pembelian (Marcelina \& Tantra, 2017). Promotion: menurut Philip Kotler dan Gery Amstrong promosi adalah aktivitas yang mengkomunikasikan keunggulan produk dan membujuk konsumen sasaran untuk membelinya (Loekito et al., 2019). Place : menurut Kotler dan Solomon adalah berbagai kegiatan yang dilakukan pelaku usaha untuk memudahkan pelanggan potensialnya mengakses produknya mudah diperoleh dan tersedia untuk konsumen sasaran (Layantara, 2016). Physical Evidence: Menurut Kotler yaitu bukti fisik yang dimiliki penyedia produk/jasa merupakan wujud nyata yang ditawarkan kepada konsumen ataupun calon konsumen (Loekito et al., 2019). People: Interaksi yang terjadi antara karyawan dan pelanggan akan memberikan dampak yang kuat bagi pelanggan terhadap pengalaman pelayanan yang diterima. Oleh karena itu, suatu pelayanan dikatakan baik apabila pegawainya memiliki keahlian teknik dalam pekerjaannya dan sikap yang positif (Layantara, 2016). Process: keseluruhan sistem yang berlangsung dalam penyelenggaraan dan menentukan mutu kelancaran penyelenggaraan jasa yang dapat 
memberikan kepuasan pada penggunanya (Loekito et al., 2019). Beberapa peneliti terdahulu berfokus pada pengaruh strategi marketing mix terhadap keputusan pembelian (Barcelona et al., 2019; Setiawan \& Sugiharto, 2014). Sedangkan penelitian ini menggunakan strategi bauran pemasaran $7 \mathrm{P}$ tersebut untuk melihat faktor keberhasilan wirausaha mahasiswa. Kajian yang dilakukan dalam penelitian ini berbeda dengan kajian yang telah dilakukan oleh (Lestari, 2019) terkait faktor yang mempengaruhi keberhasilan wirausaha mahasiswa secara umum, penelitian ini intens menganalisis faktor-faktor keberhasilan berwirausaha mahasiswa berdasarkan bauran pemasaran 7P.

\section{METODE}

Lokasi penelitian di Universitas Sebelas Maret, Kota Surakarta. Jenis penelitian, penelitian deskriptif dengan cara deskriptif kuantitatif. Penelitian dilaksanakan pada bulan Juni-September 2020. Sampel yang diambil sejumlah 70 orang mahasiswa PMW, terdiri dari 3 kelompok usaha yaitu kuliner, non kuliner dan jasa. Data diolah dengan tabulasi data, menggunakan bantuan program SPSS. Variabel penelitian adalah faktor keberhasilan wirausaha mahasiswa. Adapun indikator yang digunakan adalah elemen yang terdapat dalam Marketing Mix 7P, yaitu product, price, promotion, place, physical evidence, people dan process. Analisis data yang dilakukan yaitu dengan cara menganalisis tabel-tabel hasil respon terbanyak dari responden terhadap indikatorindikator yang terdapat di masingmasing elemen.

\section{HASIL DAN PEMBAHASAN}

\section{Profil responden}

Tabel 1. Profil Responden

\begin{tabular}{|c|c|c|c|c|}
\hline \multirow[t]{2}{*}{ No } & \multirow{2}{*}{$\begin{array}{l}\text { Jenis } \\
\text { Usaha }\end{array}$} & \multirow{2}{*}{$\begin{array}{c}\text { Profil } \\
\text { Responden }\end{array}$} & \multicolumn{2}{|c|}{ Jumlah } \\
\hline & & & F & $\%$ \\
\hline \multirow[t]{9}{*}{1} & Kuliner & Jenis Kelamin & & \\
\hline & & Perempuan & 16 & 72,7 \\
\hline & & Laki-laki & 6 & 27,3 \\
\hline & & Jumlah & 22 & 100 \\
\hline & & Lama Usaha & & \\
\hline & & 0-1 tahun & 15 & 68,2 \\
\hline & & 2 tahun & 5 & 22,7 \\
\hline & & $>2$ tahun & 2 & 9,1 \\
\hline & & Jumlah & 22 & 100 \\
\hline \multirow[t]{9}{*}{2} & Usaha & Jenis Kelamin & & \\
\hline & & Perempuan & 17 & 65,4 \\
\hline & & Laki-laki & 9 & 34,6 \\
\hline & & Jumlah & 26 & 100 \\
\hline & & Lama Usaha & & \\
\hline & & 0-1 tahun & 9 & 34,6 \\
\hline & & 2-3 tahun & 14 & 53,8 \\
\hline & & 4-6 tahun & 3 & 11,6 \\
\hline & & Jumlah & 26 & 100 \\
\hline \multirow[t]{9}{*}{3} & Usaha & Jenis Kelamin & & \\
\hline & & Perempuan & 4 & 18,2 \\
\hline & & Laki-laki & 18 & 81,8 \\
\hline & & Jumlah & 22 & 100 \\
\hline & & Lama Usaha & & \\
\hline & & 0-1 tahun & 4 & 18,2 \\
\hline & & 2 tahun & 10 & 45,5 \\
\hline & & $>2$ tahun & 8 & 36,3 \\
\hline & & Jumlah & 22 & 100 \\
\hline
\end{tabular}

Sumber: Data Primer, 2020

Dalam penelitian ini, jumlah responden laki-laki maupun perempuan seimbang. Responden usaha kuliner sebagian besar memiliki 
lama usaha 0-1 tahun. Responden usaha non-kuliner, sebagian besar memiliki lama usaha 2-3 tahun, dan responden usaha jasa memiliki lama usaha 2 tahun. Dapat dikatakan sebagian besar responden memiliki lama usaha antara 1-3 tahun. Faktorfaktor keberhasilan wirausaha mahasiswa yang dilihat dari respon dominan indikator keberhasilan usaha berbasis marketing mix 7P.

\subsection{Usaha Kuliner}

Tabel 2. Respon Dominan Mahasiswa Pelaku Usaha Kuliner Pada Indikator Keberhasilan Usaha Berbasis

\begin{tabular}{llc} 
Marketing & Mix 7P (n=22) & \\
\hline \multirow{3}{*}{$\begin{array}{l}\text { Marketing } \\
\text { mix 7P }\end{array}$} & $\begin{array}{l}\text { indikator dominan } \\
\text { keberhasilan }\end{array}$ & \multicolumn{1}{c}{ F/\% } \\
& respon \\
& Branding & $16 / 72,7$ \\
\hline Product & Garansi & $16 / 72,7$ \\
Price & Periode & $22 / 100,0$ \\
& pembayaran & \\
Promotion & Peturn & $20 / 90,9$ \\
& Periklanan & $20 / 90,9$ \\
Place & Jara penjualan & $18 / 81,8$ \\
& Lokasi usaha & $15 / 68,3$ \\
Physical & Desain produk & $14 / 63,6$ \\
evidence & & \\
People & Penanganan & $20 / 90,9$ \\
& komplain & \\
Process & Delivery service & $17 / 77,3$ \\
& (dalam kota) & \\
\hline
\end{tabular}

Sumber: Analisis data primer

Hasil penelitian menunjukkan bahwa wirausaha mahasiswa yang melakukan usaha kuliner, mayoritas menyatakan bahwa faktor-faktor keberhasilan dari elemen product, yaitu indikator branding produk dan garansi yang terjamin. Elemen price, yaitu indikator periode pembayaran dan return. Elemen promotion, yaitu indikator periklanan dan cara penjualan. Elemen place, yaitu indikator jangkauan pasar dan lokasi usaha. Elemen physical evidence, yaitu indikator desain produk. Elemen people, yaitu indikator penanganan komplain. Elemen process, yaitu indikator delivery service.

\subsection{Usaha Non Kuliner}

Tabel 3. Respon Dominan Mahasiswa Pelaku Usaha Non Kuliner Pada Indikator Keberhasilan Usaha Berbasis Marketing Mix 7P $(n=26)$

\begin{tabular}{|c|c|c|}
\hline $\begin{array}{l}\text { Marketing } \\
\text { mix 7P }\end{array}$ & $\begin{array}{l}\text { Respon dominan } \\
\text { indikator } \\
\text { keberhasilan } \\
\text { usaha tentang }\end{array}$ & $\begin{array}{l}\mathrm{F} / \% \\
\text { respon }\end{array}$ \\
\hline \multirow[t]{2}{*}{ Product } & Pelayanan & $20 / 79,6$ \\
\hline & Kemasan & 19/73,1 \\
\hline \multirow[t]{2}{*}{ Price } & $\begin{array}{l}\text { Periode } \\
\text { pembayaran }\end{array}$ & $26 / 100,0$ \\
\hline & Return & $24 / 92,3$ \\
\hline \multirow[t]{2}{*}{ Promotion } & Periklanan & $25 / 96,2$ \\
\hline & Cara penjualan & $18 / 69,2$ \\
\hline \multirow[t]{2}{*}{ Place } & Jangkauan pasar & $25 / 96,2$ \\
\hline & Lokasi usaha & $22 / 84,6$ \\
\hline \multirow[t]{2}{*}{$\begin{array}{l}\text { Physical } \\
\text { evidence }\end{array}$} & $\begin{array}{l}\text { Peralatan yang } \\
\text { mendukung }\end{array}$ & $18 / 69,2$ \\
\hline & Desain produk & $16 / 61,5$ \\
\hline \multirow[t]{2}{*}{ People } & $\begin{array}{l}\text { Penanganan } \\
\text { komplain }\end{array}$ & $26 / 100,0$ \\
\hline & Interaksi & $23 / 88,5$ \\
\hline Process & $\begin{array}{l}\text { Delivery service } \\
\text { (dalam kota) }\end{array}$ & $21 / 80,8$ \\
\hline
\end{tabular}

Sumber: Analisis data primer

Hasil penelitian menunjukkan bahwa wirausaha mahasiswa yang melakukan usaha non-kuliner, mayoritas menyatakan bahwa faktorfaktor keberhasilan dari elemen product, yaitu indikator pelayanan dan kemasan. Elemen price, yaitu indikator periode pembayaran dan return. Elemen promotion, yaitu 
indikator periklanan dan cara penjualan. Elemen place, yaitu indikator jangkauan pasar dan lokasi usaha. Elemen physical evidence, yaitu indikator peralatan yang mendukung dan desain produk. Elemen people, yaitu indikator penanganan komplain dan interaksi. Elemen process, yaitu indikator delivery service.

\subsection{Usaha Jasa}

Tabel 4. Respon Dominan Mahasiswa Pelaku Usaha Jasa Pada Indikator Keberhasilan Usaha Berbasis $\frac{\text { Marketing Mix 7P }(\mathrm{n}=22)}{\text { Respon dominan }}$

\begin{tabular}{lll}
$\begin{array}{l}\text { Marketing } \\
\text { mix 7P }\end{array}$ & $\begin{array}{l}\text { Respon dominan } \\
\text { indikator } \\
\text { keberhasilan } \\
\text { usaha }\end{array}$ & $\begin{array}{l}\text { Frek/\% } \\
\text { respon }\end{array}$ \\
\hline Product & Branding & $16 / 72,7$ \\
& Pelayanan & $16 / 72,7$ \\
Price & Periode & $22 / 100,0$ \\
& pembayaran & \\
Promotion & Diskon & $17 / 77,3$ \\
& Periklanan & $20 / 90,9$ \\
Place & Cara penjualan & $17 / 77,3$ \\
& Jangkauan pasar & $15 / 68,2$ \\
& Keunikan & $22 / 88,2$ \\
Physical & tempat & \\
evidence & Peralatan yang & $15 / 68,2$ \\
People & menunjang & \\
& Penanganan & $19 / 86,9$ \\
& komplain & \\
Process & Rekruitmen & $17 / 77,3$ \\
& Delivery service & $14 / 63,6$ \\
(dalam kota) & \\
\hline
\end{tabular}

Sumber: Analisis data primer

Hasil penelitian menunjukkan bahwa wirausaha mahasiswa yang melakukan usaha jasa, mayoritas menyatakan bahwa faktor-faktor keberhasilan dari elemen product, yaitu indikator branding produk dan pelayanan. Elemen price, yaitu indikator periode pembayaran dan return. Elemen promotion, yaitu indikator periklanan dan cara penjualan. Elemen place, yaitu indikator jangkauan pasar dan keunikan tempat. Elemen physical evidence, yaitu indikator peralatan penunjang. Elemen people, yaitu indikator penanganan komplain dan rekruitmen. Elemen process, yaitu indikator delivery service.

Faktor keberhasilan wirausaha mahasiswa yang dilihat dari elemen produk, meliputi branding, kemasan, pelayanan dan garansi. Branding berkaitan dengan kompetitor. Wirausaha Mahasiswa berpendapat bahwa dengan strategi branding mereka ingin menempatkan produk pada posisi bersaing kompetitif dengan produk lain (Nastain, 2017). Branding dilakukan dengan memberi merk pada produk yang mudah diingat serta logo yang menarik juga tagline yang unik, sehingga dapat mewakili produk yang di branding. Kemasan, banyak digunakan pada usaha kuliner dan non kuliner, maka harus dilengkapi dengan logo/label, merk. Kemasan dibuat unik, sesuai dengan produk, dibuat berbagai ukuran dan bentuk untuk memenuhi kebutuhan konsumen, dapat didaur ulang, dibuat sesuai karakter konsumen. Pembuatan kemasan ini penting, karena kemasan, yang berhadapan langsung dengan konsumen. Oleh sebab itu efek indra yang spontan ketika melihat kemasan, akan mempengaruhi tindakan konsumen di tempat penjualan (Apriyanti, 2018). Pada usaha jasa, kemasan tidak begitu penting, yang dibutuhkan pelaku usaha jasa adalah testimoni tentang jasa tersebut dari 
konsumen. Biasanya konsumen meletakkan di media sosial.

Pelayanan, berkaitan dengan respon pesanan konsumen, maka yang dinilai oleh konsumen adalah kualitas pelayanan, yang ada hubungannya dengan perilaku pembelian berulang (Purbasari \& Purnamasari, 2018) Setiap usaha, berbeda-beda dalam memberikan respon, sangat tergantung pada produknya. Garansi berkaitan dengan janji pelaku usaha secara formal tentang layanan yang akan mereka terima, pasca pembelian. Salah satu janji tersebut, jika terjadi masalah dengan produk yang dibeli, maka ada kemudahan mengembalikan maupun penukaran barang. Ini menjadi daya tarik bagi konsumen. Garansi berkaitan dengan kepuasan pelayanan. Tanpa adanya garansi pelayanan, ketidak puasan yang dirasakan konsumen tidak tersampaikan kepada pelaku usaha (Tiasto, 2014).

Faktor keberhasilan wirausaha mahasiswa yang dilihat dari elemen price meliputi periode pembayaran dan return. Periode pembayaran berkaitan dengan cara pembayaran secara tunai maupun kredit. Hal tersebut merupakan faktor yang juga harus dipertimbangkan dalam menetapkan harga (Fatihudin \& Firmansyah, 2019). Kredit berupa angsuran harian, mingguan maupun bulanan. Yang menjadi faktor keberhasilan usaha adalah bila periode pembayaran ini tunai. Pembayaran tunai sangat menguntungkan pelaku usaha, karena modal cepat kembali dan dapat digunakan lagi untuk produksi.
Return berkaitan dengan tukar tambah barang lama dengan barang baru. Untuk mendongkrak pembelian pelaku usaha membuat aturan return yang dianggap menguntungkan konsumen. Return merupakan faktor keberhasilan usaha, karena diharapkan terjadi peningkatan penjualan. Diskon, berkaitan dengan pemberian potongan harga, yang biasanya diberikan diawal usaha. Menurut Kotler dan Amstrong diskon adalah pengurangan harga langsung terhadap suatu pembelian dalam periode waktu tertentu, diskon kepada konsumen memiliki tujuan untuk menghargai respon pelanggan. Adanya diskon menimbulkan ketertarikan konsumen untuk membeli (Putra et al., 2016). Oleh sebab itu diskon menjadi faktor keberhasilan wirausaha.

Faktor keberhasilan wirausaha mahasiswa yang dilihat dari elemen promotion, meliputi periklanan dan cara penjualan. Periklanan, berkaitan dengan pesan-pesan penjualan yang paling persuasif yang diarahkan kepada calon konsumen yang paling potensial atas produk barang atau jasa tertentu dengan biaya yang semurah-murahnya. Hasil penelitian (Sihombing \& Fauzi, 2019) periklanan berpengaruh terhadap penjualan. Media periklanan yang dipilih adalah TTL (Through the Line) yaitu Media Sosial, karena terjangkau, tepat sasaran, dan mudah tersampaikan.

Cara penjualan, berkaitan dengan media penjualan yang menurut para wirausaha mahasiswa dapat meningkatkan penjualan adalah online dan offline agar dapat menjangkau semua target market. Online marketing di media sosial 
dilakukan agar target market yang sedang berselancar dapat melihat iklan tersebut. Offline marketing, dilakukan dengan menyampaikan informasi secara langsung. Ketertarikan pada informasi tersebut karena lebih dimengerti maksud dan tujuannya (Pribadi \& Mulyana, 2018).

Faktor keberhasilan wirausaha mahasiswa yang dilihat dari elemen place, meliputi jangkauan pasar dan lokasi usaha, keunikan tempat. Jangkauan pasar berkaitan dengan online marketing, yang mampu menjangkau keluasan yang tidak berbatas wilayah. Pelaku usaha yang mampu menjangkau pasar baik secara online maupun offline maka usahanya berhasil. Jangkauan pasar online dapat menjangkau konsumen yang lebih luas dalam memperkenalkan produk, karena melalui internet tidak terbatas ruang dan waktu, serta tersedia untuk diakses setiap saat (Widayati, 2018).

Lokasi usaha, terkait dengan baik secara online yang disebut marketspace maupun secara offline marketing yang disebut marketplace. Lokasi dipilih untuk mempermudah akses pelanggan (Fu'ad, 2015). Keunikan tempat usaha berkaitan dengan keunikan yang dimiliki dibandingkan dengan pesaing, untuk menarik minat beli konsumen. Menarik minat beli konsumen untuk melakukan pembelian juga dapat dilakukan dengan cara memberikan keunikan tempat yang menyenangkan bagi kosumen. Melalui keunikan tempat yang sengaja diciptakan, berupaya untuk mengkomunikasikan informasi yang terkait dengan layanan, harga maupun ketersediaan barang dagangan (Hotman et al., 2017).
Faktor keberhasilan wirausaha mahasiswa yang dilihat dari elemen physical evidence, meliputi desain produk dan peralatan penunjang. Desain produk dari ide sendiri diyakini sebagai faktor keberhasilan usaha. Menurut (Kotler dan Armstrong, 2013), desain produk merupakan segala sesuatu yang melekat dan menyertai produk tersebut, seperti gaya hidup, fitur dan bentuk atau penampilan produk. Desain produk dibuat agar produk dapat diterima oleh masyarakat, mempunyai kualitas yang baik, harga yang terjangkau, dan menarik (Susetyarsi, 2013). Peralatan penunjang, berkaitan dengan cara memproduksi produk tentang penggunaan alat penunjang. Wirausaha mahasiswa menyakini bahwa penggunaan kombinasi alat manual dengan alat penunjang akan mempercepat proses produksi, yang selanjutnya menjadi faktor keberhasilan usaha.

Faktor keberhasilan wirausaha mahasiswa yang dilihat dari elemen people, meliputi penanganan komplain, interaksi dan rekruitmen. Penanganan komplain berkaitan dengan pelayanan pasca pembelian. Penanganan pengaduan/komplain terhadap ketidakpuasan atas pelayanan yang konsumen terima, serta usaha untuk memperbaiki masalah yang timbul, akan mendorong persepsi pelanggan terhadap citra usaha sehingga akan menaikkan keuntungan jangka panjang bagi penyedia produk/jasa (Ravenska, 2019). Interaksi dengan konsumen, bentuknya berupa pemberian solusi kepada konsumen dalam melakukan pembelian dengan 
keputusan yang sulit. Pelaku usaha sangat berperan dalam proses pemasaran (Pradipta \& Rastini, 2012).

Rekruitmen, berkaitan dengan proses mengumpulkan informasi yang relevan tentang tugas-tugas terkait pekerjaan dan karakteristik manusia yang diperlukan untuk melakukan pekerjaan. Perekrutan akan memainkan peran strategis dalam bisnis perusahaan. Strategi rekrutmen yang tepat akan menghasilkan sumberdaya manusia sesuai dengan kebutuhan bisnis perusahaan melalui penentuan kualifikasi yang sesuai berdasarkan pendidikan dan keahlian. Keberadaan karyawan yang handal dipandang sebagai motor penggerak bagi setiap kegiatan usaha yang akan mendorong keberhasilan usaha (Chungyalpa \& Karishma, 2016).

Faktor keberhasilan wirausaha mahasiswa yang dilihat dari elemen process, meliputi delivery service. Delivery service sesuai dengan jangkauan pasar. Wirausaha mahasiswa masih berkemampuan melakukan delivery service di wilayah dalam kota. Delivery service mampu memberikan daya tarik bagi konsumen untuk memenuhi kebutuhannya, konsumen dengan mudah bisa mengetahui beragam alternatif harga disertai dengan tampilan produk yang ada hanya melalui gadget yang dimiliki (Taufik et al., 2020).

\section{KESIMPULAN}

Semua kelompok usaha, baik kuliner, non kuliner maupun jasa memiliki faktor-faktor keberhasilan wirausaha mahasiswa. Diantara mereka ternyata ada persamaan dan perbedaan di masing-masing elemen baik pada product, price, promotion, place, physical evidence, people dan process. Pada usaha kuliner dan non kuliner, faktor keberhasilan yang sama yaitu pada elemen price, promotion, place, people dan process. Pada usaha kuliner, non kuliner dan jasa, faktor keberhasilan yang sama terletak pada elemen process saja. Kesamaan yang tidak terdapat di semua elemen, menunjukkan bahwa faktor keberhasilan yang terdapat di tiga kelompok usaha, memiliki keunikan masing-masing. Penelitian ini terbatas hanya meneliti di satu perguruan tinggi negeri saja sehingga dapat digunakan untuk peneliti lain sebagai acuan meneliti lebih luas lagi.

\section{DAFTAR PUSTAKA}

Apriyanti, M. E. (2018). Pentingnya kemasan terhadap penjualan produk perusahaan. Sosio E-Kons, 10(1), https://doi.org/10.30998/sosioe kons.v10i1.2223

Barcelona, O., Tumbel, T. M., \& Kalangi, J. A. F. (2019). Pengaruh marketing mix terhadap keputusan pembelian pada CV. Justiti Motor Lembata. Jurnal Administrasi Bisnis, 8(2), 34. https://doi.org/10.35797/jab.8.2. 2019.23560.34-42

Chungyalpa, W., \& Karishma, T. (2016). Best practices and emerging trends in recruitment and selection. Journal of Entrepreneurship $\mathcal{E}$ Organization 
Management,

05(02).

https://doi.org/10.4172/2169-

026x.1000173

Endriani, A., \& Hasrul, H. (2020). Evaluasi program mahasiswa wirausaha tahun 2018 di universitas negeri Padang. Journal of Civic Education, 3(1), 92100.

https:// doi.org/10.24036/jce.v3i 1.324

Fatihudin, D., \& Firmansyah, A. (2019). Pemasaran Jasa: Strategi, Mengukur Kepuasan, dan Loyalitas Pelanggan. Deepublish.

Fu'ad, E. N. (2015). Pengaruh pemilihan lokasi terhadap kesuksesan usaha berskala mikro/kecil di komplek shopping centre Jepara. Media Ekonomi Dan Manajemen, 30(1), 56-67.

Harini, C., \& Yulianeu, Y. (2018). Strategi penetrasi pasar UMKM Kota Semarang menghadapi era pasar global MEA. Jurnal Ekonomi Dan Bisnis, 21(2), 361-381. https://doi.org/10.24914/jeb.v21 i2.1967

Hartanty, I. T., \& Rahmawati, A. (2013). Peningkatan kinerja pemasaran melalui optimalisasi keunggulan bersaing. Ekobis, 14(2), 72-89. https:// core.ac.uk/download/p df/236373998.pdf

Hartono, H. (2018). Kajian capaian program mahasiswa wirausaha. Jurnal Aktual Akuntansi Keuangan Bisnis Terapan (AKUNBISNIS), 1(2), 152-159. https://doi.org/10.32497/akunbi snis.v1i2.1230

Hotman, M., \& Hidayat. (2017). Pengaruh suasana toko dan lokasi terhadap minat beli ulang konsumen di UD. Naysila Toys Simpang SKPD. Jurnal Mahasiswa Prodi Manajemen Fakultas Ekonomi, 2(2), 1-10.

Kotler, P., dan Armstrong, G. (2013). Prinsip-prinsip Pemasaran Edisi 12 Jilid 1, Diterjemahkan oleh Bob Sabran (12th ed.). Erlangga.

Layantara, S. (2016). Evaluasi perkembangan bbq street menggunakan teori marketing mix $7 p$ terhadap fenomena food truck di Surabaya. Jurnal Manajemen Dan Start-Up Bisnis, 1(1), 243-250. https://journal.uc.ac.id/index.p hp/performa/article/view/147

Lestari, F. A. P. (2019). Faktor-faktor yang mempengaruhi keberhasilan berwirausaha. Jurnal Riset Inspirasi Manajemen Dan Kewirausahaan, 3(2), 65-69.

Loekito, M., Irawan, C., Nugroho, A., \& Kartika, E. W. (2019). Analisa pengaruh marketing mix (7p) terhadap keputusan pembelian di folks! coffee shop and tea house Surabaya. Manajemen Perhotelan, 1-15.

Marcelina, J., \& Tantra, B. (2017). Pengaruh marketing mix (7P) terhadap keputusan pembelihan pada guest house di Surabaya. Program Manajemen Perhotelan, Fakultas Ekonomi, Universitas Kristen Petra, Surabaya, Indonesia., $5(2)$.

Nastain, M. (2017). Branding dan 
eksistensi produk (kajian teoritik konsep branding dan tantangan eksistensi produk). CHANNEL: Jurnal Komunikasi, 5(1), 14-26. https://doi.org/10.12928/chann el.v5i1.6351

Pradipta, I. N. M. A. W., \& Rastini, N. M. (2012). Pembeli terhadap keputusan impulse buying di carrefour hypermarket. Ekonomi Dan Bisnis, 2242-2259.

Pribadi, D., \& Mulyana, M. (2018). Pengaruh online marketing dan offline marketing terhadap brand association McDonald's. Studi Kasus, July. https:// doi.org/10.13140/RG.2.2 .24355 .55845

Purbasari, D. M., \& Purnamasari, D. L. (2018). Pengaruh kualitas pelayanan dan nilai pelanggan terhadap kepuasan pelanggan. Jurnal Inspirasi Bisnis $\mathcal{E}$ Manajemen, 2(1), 43-54. https:// doi.org/10.34308/eqien. v6i2.93

Putra, E., Kumadji, S., \& Yulianto, E. (2016). Pengaruh diskon terhadap minat beli serta dampaknya pada keputusan pembelian (Study pada konsumen yang membeli produk diskon di Matahari Department Store Pasar Besar Malang). Jurnal Administrasi Bisnis S1 Universitas Brawijaya, 38(2), 184-193.

Ratnasari, E., Hakim, A., \& Hayat, A. (2013). Implementasi Program Mahasiswa Wirausaha (PMW) dalam mewujudkan mahasiswa enterpreneur (Studi pada Universitas Brawijaya Malang). Jurnal Administrasi Publik
Mahasiswa Universitas Brawijaya, 1(6), 1276-1285.

Ravenska, J. (2019). Pengaruh penanganan keluhan, pemulihan layanan dan nilai jasa terhadap kepuasan pelanggan menggunakan jasa Go-jek. 3.

Rohmaniyah, A., \& Nurhayati, T. (2017). Peningkatan kreativitas pemasaran dan kualitas networking berbasis orientasi pasar terhadap kinerja pemasaran. Jurnal Ekonomi Dan Bisnis, 18(2), 149. https://doi.org/10.30659/ekobis. 18.2.149-163

Romli, M. E. (2019). Analisis tentang faktor penyebab kewirausahaan belum dapat mensejahterakan kehidupan penduduk. Jurnal Media Wahana Ekonomika, 15(4), 48.

https://doi.org/10.31851/jmwe. v15i4.3057

Ruliah, R., \& Susanto, D. (2015). Penerapan metode marketing mix 7p untuk perumusan strategi pemasaran jasa. Progresif: Jurnal Ilmiah Komputer, 919-930. http:/ /ojs.stmikbanjarbaru.ac.id/index.php/prog resif/article/view/48

Sativana, P. D., Tripalupi, L. E., \& Meitriana, M. A. (2014). Tingkat keberhasilan Program Mahasiswa Wirausaha (PMW) di Undiksha ditinjau dari aspek unit bisnis tahun 2012. Jurnal Jurusan Pendidikan Ekonomi Undiksha, 4(1).

Setiawan, I., \& Harmon, H. (2017). Bisnis olah raga: peran bauran pemasaran pada keberhasilan 
usaha. Jurnal Riset Bisnis Dan Investasi, $\quad 3(1)$, 13. https:// doi.org/10.35697/jrbi.v3i 1.542

Setiawan, W., \& Sugiharto, S. (2014). Pengaruh marketing mix terhadap keputusan pembelian toyota avanza tipe G di Surabaya. Jurnal Strategi Pemasaran, 2(1).

Sihombing, D. S., \& Fauzi, A. (2019). Pengaruh periklanan terhadap penjualan (Studi kasus pada PT. Samekarindo Indah, Balikpapan). Jurnal Administrasi Bisnis, Vol. 71(1), 71-80.

Suarmawan, K. A. (2015). Analisis Faktor - Faktor yang Mempengaruhi Keberhasilan Usaha Mikro dan Kecil (Studi pada Usaha Kerajinan Ingka di Desa Bulian, Kec. Kubutambahan). Jurnal Jurusan Pendidikan Ekonomi (JJPE), 5(1), 110.

Suryana, Y. (2016). Kewirausahaan: pendekatan karakteristik wirausahawan sukses ed.2. In Proceedings of ICMSTEA 2016.

Susetyarsi, T. (2013). Analisis pengaruh strategi desain produk terhadap minat beli konsumen pada skuter matik yamaha merek mio fino di kota Semarang. Jurnal STIE Semarang, 5(2), 33-49.

Taufik, M. A., Kurniawan, I., \& Karno. (2020). Peranan platform food delivery service dalam mendukung marketing mix UKM di masa new normal. Jurnal Pengembangan Wiraswasta, 22(02), 121-130.

Tiasto, E. (2014). Pengaruh garansi layanan: evaluasi konsumen pada pasca pembelian (Studi pada pengguna jasa layanan ekspedisi JNE). Jurnal Repository UII Yogyakarta, 2(1), 1-27.

Wartika, I. W. (2015). Analisis faktor penyebab kegagalan usaha penerima Program Mahasiswa Wirausaha (PMW) di Universitas Pendidikan Ganesha (Undiksha tahun 2013). Ekuitas: Jurnal Pendidikan Ekonomi, 5(1). https://doi.org/10.23887/ekuita s.v3i1.12775

Wheelen, T. L., \& Hunger, D. J. (2012). Strategic management and business policy toward global sustainability thirteenth edition. Strategic Management and Business Policy Toward Global Sustainability.

Widayati, E., Yunaz, H., Rambe, T., Siregar, B. W., Fauzi, A., \& Romli, R. (2019). Pengembangan kewirausahaan dengan menciptakan wirausaha baru dan mandiri. JMBI UNSRAT (Jurnal Ilmiah Manajemen Bisnis Dan Inovasi Universitas Sam Ratulangi)., 6(2), 98-105. https://doi.org/10.35794/jmbi.v 6i2.26181

Widayati, K. D. (2018). Implementasi SWOT strategi pemasaran online dan offline pada PT Roti Nusantara Prima cabang Jatiasih, Bekasi. Jurnal Sekretari Dan Manajemen, 2(2), 209-2016. http:/ / ejournal.bsi.ac.id/ejurnal /index.php/widyacipta 